\title{
Glucose-1-Phosphate-Induced Accumulation of Intracellular Starch: a Distinguishing Feature of Certain Corynebacteria
}

\author{
SHELDON B. ARDEN and LANE BARKSDALE
}

Department of Microbiology, New York University Medical Center, New York, New York 10016

\begin{abstract}
Fifty-seven bacterial strains, including corynebacteria, "plant pathogenic corynebacteria," mycobacteria, and nocardias, were examined (aerobically and anaerobically) for their capacity to produce a glucan phosphorylase $(\alpha-1,4$ glucan:orthophosphate glucosyl transferase, EC 2.4.1.1), which synthesizes an iodinophilic starch-like polysaccharide from glucose-1-phosphate. Only Corynebacterium diphtheriae, $C$. belfanti, $C$. ulcerans, $C$. ovis, $C$. kutscheri, $C$. minutissimum, and two (out of eight) strains of $C$. renale yielded positive results. The presence of glucose-1-phosphate-induced starch-like material appears to be a valid additional means of distinguishing most true corynebacteria from mycobacteria and nocardias.
\end{abstract}

In a systematic search for genetic markers which are of taxonomic value in the characterization of corynebacteria, mycobacteria and nocardias, we have investigated the nature and distribution of a corynebacterial glucan phosphorylase responsible for the starch-like, iodinophilic material discovered in certain strains of $C$. diphtheriae by Hehre, Carlson, and Neill in 1974 (7). These authors found that a number of strains of Corynebacterium diphtheriae produced iodinophilic intracellular inclusions when grown in the presence of glucose-1-phosphate (G-1-P). The iodinophilic polysaccharide from a mitis strain of $C$. diphtheriae was analyzed by Carlson and Hehre (3) and shown to consist of an amylose and an apparently unique amylopectin. Later, Carrier and McCleskey (4) found that glucose-6-phosphate (G-6-P) could not substitute for G-1-P in the synthesis of iodinophilic material by certain corynebacteria, and they suggested that the corynebacterial glucan phosphorylase transferred glycosyl units (from G-1-P) to the growing polysaccharide chain with the concomitant release of orthophosphate.

The strains employed in this study are given in Table 1. All cultures to be tested, with three exceptions, were inoculated on agar (contained in petri dishes) of the following composition: tryptose (Difco), 1\% (wt/vol); yeast extract (Difco), 0.3\% (wt/vol); glucose, $0.5 \%$ (wt/vol); $\mathrm{K}_{2} \mathrm{HPO}_{4}, 0.006 \mathrm{M}$; G-1-P (crystalline dipotassium salt, Sigma Chemical Co.), 0.013 M; and agarose, $1.5 \%$ (wt/vol), final $\mathrm{pH}, 6.9$. For tests carried out in the absence of orthophosphate, $\mathrm{K}_{2} \mathrm{HPO}_{4}$ was omitted. When glucose was omitted, an equal amount of either fructose, galactose, maltose, sucrose, or glycerol was used in its place. An ideal medium for routine screening was found to be the above formula containing $0.5 \%$ glucose. Intermedius strains $(C$. diphtheriae) and $C$. bovis ATCC 7715 required the addition of $5 \%$ (vol/vol) horse serum (BBL). Mycobacterium bovis strain BCG was grown on Dubos agar to which had been added phosphate, glucose, and G-1-P..All tests were carried out on duplicate plates, one set being incubated under standard atmospheric conditions and the second being incubated in a mixture of $10 \%$ $\mathrm{CO}_{2}$ in nitrogen maintained at $3 \mathrm{lb} / \mathrm{in}^{2}$. Except for the "plant pathogenic corynebacteria," incubated at $26 \mathrm{C}$, all cultures were incubated at $36 \mathrm{C}$. Inoculation was accomplished by placing drops of bacteria, actively grown in the absence of G-1-P, at specific sites on agar plates. The period of incubation was determined by the length of time it took to obtain dense growth, usually 2 to 3 days. After incubation, the plates were flooded with Gram's iodine ( $2 \mathrm{~g}$ of iodine dissolved in $10 \mathrm{ml}$ of $1 \mathrm{~N} \mathrm{NaOH}$ and brought to $100 \mathrm{ml}$ final volume with distifled water [8]). Positive reactions given by bacterial masses ranged from a light gray (weak reaction) to a grayish-blue (intermediate reaction) to an intense blue-black (strong reaction) color.

We have found that corynebacterial glucan phosphorylase(s) is produced under aerobic and anaerobic conditions of growth. We feel that it should be classified properly as an $\alpha$-1,4-glucan: orthophosphate glucosyl transferase (EC 2.4.1.1) because its requirement for G-1-P could not be satisfied by G-6-P and because it was inhibited by suitable concentrations of orthophosphate. When the concentration of 
TABLE 1.

\begin{tabular}{|c|c|}
\hline Organism $^{a}$ & $\begin{array}{l}\text { Intensity of starch- } \\
\text { iodine interaction }\end{array}$ \\
\hline $\begin{array}{l}\text { Corynebacterium diphtheriae, } \\
\text { types: } \\
\text { mitis }(8)^{c} \ldots \ldots \ldots \ldots \ldots \\
\text { gravis }(4), \text { intermedius }(2) \ldots\end{array}$ & Strong \\
\hline C. belfanti (2), C. ulcerans (3). . & Strong \\
\hline C. ovis $(4)^{d} \ldots \ldots \ldots \ldots \ldots$ & Weak to moderate \\
\hline C. kutscheri, C. minutissimum & Moderate to strong \\
\hline C. renale $(2)^{e} \ldots \ldots \ldots \ldots$ & Strong \\
\hline C. renale $(6)^{e} \ldots \ldots \ldots \ldots \ldots$ &.- \\
\hline C. xerosis (4)........... & $\because$ to weak \\
\hline $\begin{array}{l}\text { C. bovis, } C \text {. fermentans (2), } \\
\text { C. hofmanni (3) } \ldots \ldots\end{array}$ & \\
\hline C. equi, ${ }^{f}$ C. rubrum (2) ${ }^{f, g} \ldots$ & - \\
\hline $\begin{array}{l}\text { C. betae, } C \text {. fascians, } C \text {. poin- } \\
\text { settiae, } C \text {. sepedonicum } \\
\text { Mycobacterium bovis strain }\end{array}$ & - \\
\hline $\begin{array}{c}\text { BCG, } \ldots \ldots \ldots \ldots \\
\text { M. sp. } 607, \text { M. fortuitum, } \\
\text { M. phlei, . . } \\
\text { M. rhodochrous } f \ldots \ldots \ldots\end{array}$ & - \\
\hline
\end{tabular}

$a$ Except where otherwise indicated, all strains and their origins are to be found in reference 1 .

${ }^{b}$ Strong, black to dark blue-black; moderate, gray to gray black; weak, faint gray to light gray; negative $(-)$, no color change.

c Numbers in parentheses are the numbers of strains tested. In the case of organisms not followed by a number, a single strain was used.

${ }^{d} C$. ovis strains always gave weak to relatively moderate reactions, even when the concentration of G-1-P in the medium was increased up to fourfold.

$e$ Strong positive strains were numbers 45 and 46 ; negative strains were numbers $8,9,42,71, \mathrm{H}-25$ (12), and ATCC 19412.

${ }^{f}$ Have properties common to species of Nocardia (see Gordon [6] and Lechevalier [9]).

${ }^{g}$ Crowle (5) and Serrano (11).

orthophosphate. When the concentration of orthophosphate in the medium was much in excess of the concentration of G-1-P, the amount of iodinophilic material formed was reduced or undectable. In the presence of such high concentrations of orthophosphate (broth cultures), phosphorolysis of preformed iodinophilic material took place. Cultures of corynebacteria yielded detectable amounts of starch only when a fermentable sugar was present in the medium and when the pH was below 6.2. Growth of most strains was inhibited below $\mathrm{pH}$ 5.5. Of the sugars tested, glucose proved to give best yields of starch, followed by fructose, galactose, maltose, and glycerol, more or less in that order. One mitis strain of $C$. diphtheriae, A-16, which ferments sucrose (obtained from the collection of the Armed Forces Institute of Pathology, Washington, D.C., originally from Mauss and Keown [10]) gave good yields of starch when grown with sucrose. The starch product formed by any one of these strains could be degraded by salivary amylase, as detected by the complete loss of iodine-staining material, when the cells had been previously heated to $100 \mathrm{C}$ for $10 \mathrm{~min}$, cooled, and exposed to the enzyme (4).

We have examined representative members of the genera Cornyebacterium, Mycobacterium, and Nocardia (Table 1) for their capacity to form iodinophilic material from G-1-P. The results given herein indicate that among the organisms studied the presence of a glucan phosphorylase activity responsible for starch accumulation from G-1-P seems peculiar to Corynebacterium diphtheriae and the closely related species $C$. belfanti, $C$. ulcerans, and $C$. ovis (2), as well as C. kutscheri, C. minutissimum, and two strains of $C$. renale. The four strains of $C$. xerosis tested gave weak to negative results under our conditions.

The demonstration of the presence or $a b$ sence of G-1-P-induced starch-like material by the methods outlined in this paper would appear to offer an additional means for distinguishing most true corynebacteria (2) from mycobacteria and nocardias. True corynebacteria referred to here are those sharing the essential properties found in the type species, $C$. diphtheriae, which include nucleic acid having a guanine plus cytosine content of $\pm 55 \%$, cell walls whose murein contains glucosamine, meso- $\alpha, \epsilon$-diaminopimelic acid, and arabinogalactan, and mannan in conjunction with the $\alpha$-branched, $\beta$-hydroxylated corynomycolic acids of carbon numbers 28 to 38 .

We are grateful to Geraldine Hodgson for help with the manuscript and to Yoshie Hervey and Ivy C. Roker for expert technical assistance.

This work was supported by Public Health Service grant AI-01071 from the National Institute of Allergy and Infectious Diseases.

\section{REPRINT REQUESTS}

Address reprint requests to: Dr. Lane Barksdale, Department of Microbiology, New York University Medical Center, 550 First Avenue, New York, N.Y. 10016.

\section{LITERATURE CITED}

1. Arden, S. B., W.-H. Chang, and L. Barksdale. 1972. Distribution of neuraminidase and $N$-acetylneuraminate lyase activities among corynebacteria, 
mycobacteria and nocardias. J. Bacteriol. 112:1206-1212.

2. Barksdale, L. 1970. Corynebacterium diphtheriae and its relatives. Bacteriol. Rev. 34:378-422.

3. Carlson, A. S., and E. J. Hehre. 1949. Composition of the starch synthesized from glucose-1phosphate by diphtheria bacilli. J. Biol. Chem. 177:281-293.

4. Carrier, E. B., and C. S. McCleskey. 1962. Intracellular starch formation in corynebacteria. J. Bacteriol. 83:1029-1036.

5. Crowle, A. J. 1962. Corynebacterium rubrum nov. spec. a gram-positive nonacid-fast bacterium of unusually high lipid content. Antonie van Leeuwenhoek J. Microbiol. Serol. 28:183-193.

6. Gordon, R. E. 1966. Some strains in search of a genus-Corynebacterium, Mycobacterium, Nocardia or what? J. Gen. Microbiol. 43:329-343.

7. Hehre, E. J., A. S. Carlson, and J. M. Neill. 1947. Production of starch-like material from glucose-1- phosphate by diphtheria bacilli. Science 106: 523-524.

8. Kopeloff, N., and P. Beerman. 1922. Modified Gram stains. J. Infect. Dis. 31:480-482.

9. Lechevalier, M. P., A. C. Horan, and H. Lechevalier. 1971. Lipid composition in the classification of nocardiae and mycobacteria. J. Bacteriol. 105:313-318.

10. Mauss, E. A., and M. J. Keown. 1946. Saccharosefermenting diphtheria bacilli. Science 104:252-253.

11. Serrano, J. A., R. V. Tablante, A. A. de Serrano, G. C. de San Blas, and T. Imaeda. 1972. Physiological, chemical and ultrastructural characteristics of Corynebacterium rubrum. J. Gen. Microbiol. 70:339-349.

12. Yanagawa, R., H. Basri, and K. Otsuki. 1967. Three types of Corynebacterium renale classified by precipitin reactions in gels. Jap. J. Vet. Res. 15:111-118. 